\title{
Partial cloning of the genome of an unusual shrimp parvovirus (HPV): use of gene probes in disease diagnosis
}

\author{
Jocelyne Mari ${ }^{1}$, Donald V. Lightner ${ }^{1}$, Bonnie T. Poulos ${ }^{1}$, Jean-Robert Bonami ${ }^{2}$ \\ ${ }^{1}$ Department of Veterinary Science, The University of Arizona, Tucson, Arizona 85721, USA \\ ${ }^{2}$ Laboratoire de Pathologie Comparée, INRA-CNRS, Université Montpellier II, Place E. Batallon, \\ F-34095 Montpellier Cedex 5, France
}

\begin{abstract}
The DNA genome of the hepatopancreatic parvovirus (HPV) of penaeid shrimp was partially cloned. The largest insert obtained, from the clone OF44, was $2.3 \mathrm{kbp}$ in size and characterized by mapping with restriction enzymes. It was used to construct 2 different DIG-11 dUTP labelled probes, which appeared specific to the virus, without any cross-reactivity with uninfected tissues or with a second shrimp parvovirus, infectious hypodermal and haematopoietic necrosis virus (IHHNV). In situ hybridization on paraffin sections of the hepatopancreas of infected and uninfected shrimp showed the probes react with infected tissue and not with uninfected tissue. In positive hepatopancreas, the probes produced a strong labelling of infected nuclei, especially of the nucleolus and the karyoplasm peripheric to the intranuclear inclusion body. Intranuclear inclusion bodies, which are the principal diagnostic feature of HPV infections by histology, also reacted with the probes, but less intensely. In heavily infected hepatopancreas, cell debris reacted strongly with the probes, as did the microvilli on the surface of epithelial cells.
\end{abstract}

KEY WORDS: HPV · Parvoviridae Penaeid shrimp · Cloning - Gene probes I In situ hybridization

\section{INTRODUCTION}

The recent development of penaeid shrimp culture in numerous countries of the Americas and Southeast Asia has resulted in a concomitant increase in knowledge of growth-limiting factors, in particular, biotic factors such as disease. Among these, viral diseases are very important because some are accompanied by serious crop and economic losses. Their diagnosis is difficult and treatment for them is not available. The only way currently available to control such diseases is to avoid the use of infected stock based on early disease diagnosis. For this reason, new highly sensitive diagnostic tools, such as molecular probes and monoclonal antibodies, were recently developed for some shrimp virus diseases, i.e. IHHN (infectious hypodermal and haematopoietic necrosis) (Mari et al. 1993, Poulos et al. 1994a), MBV-type (monodon baculovirus) (Poulos et al. 1994b) and BP-type (baculovirus penaei) diseases (Bruce et al. 1993, Bonami et al. 1995).
Hepatopancreatic parvo-like virus (HPV) disease was first reported in Penaeus chinensis (= orientalis) from China, P. merguiensis from Singapore, P. semisulcatus from Kuwait and P. monodon from the Philippines (Lightner \& Redman 1985). Its natural host range also includes $P$. vannamei, $P$. esculentus, $P$. indicus and $P$. penicillatus, and its known geographic distribution corresponds to the Indo-Pacific area (China, Korea, Taiwan, Philippines, Malaysia, Singapore, Indonesia, Thailand and Australia), Africa (Kenya), the Middle East (Israel and Kuwait), and the Americas (Brazil, Ecuador, Mexico and Hawaii) (Lightner \& Redman 1992, Lightner 1993).

Recognized as closely related to the Parvoviridae by its morphology and the histopathology it causes (Lightner \& Redman 1985, Bonami \& Lightner 1991), the virus was recently isolated and characterized as an unusual parvovirus (Bonami et al. in press).

We report here our results on the partial cloning of its genome, the construction of specific genomic 
probes, and their use for the diagnosis of the disease either using dot-blot or in situ hybridization assays.

\section{MATERIAL AND METHODS}

Viral strain used, purification and DNA extraction. In order to characterize HPV, we used samples from the same batch of juvenile Penaeus chinensis (= orientalis) that originated from Korea (Bonami et al in press). Virus purification and DNA extraction were accomplished according to the protocol described in Bonami et al. (in press).

Enzymes. Restriction enzymes and mung bean nuclease (MBN) (Boehringer, Mannheim, Germany) were used according to the manufacturers' instructions. T4DNA ligase was from Boehringer, and was used according to Maniatis et al. (1982).

Agarose gel electrophoresis. Agarose gel electrophoresis was performed in $0.5 \times$ TBE buffer (Sambrook et al. 1989) and visualized under UV light with ethidium bromide $\left(0.5 \mu \mathrm{g} \mathrm{m}^{-1}\right)$ incorporated in the gel. Phage Lambda-Hind III and Lambda-Hind III/Eco RI digests were used as molecular weight markers. DIGlabelled DNA molecular weight marker II (Boehringer) was used before Southern transfer. After electrophoresis, DNA bands of interest were excised and the DNA was recovered using the GENECLEAN II kit (BIO 101) for gels run with DNA-grade agarose (BIO RAD). We also occasionally used the enzyme agarase (Boehringer) for gels run with low melting point SeaPlaque GTG agarose (FMC) prior to precipitation of the DNA.

Cloning of the genome. One part of the extracted DNA was treated with the DNA polymerase I, Klenow fragment (Boerhinger) under standard conditions (Maniatis et al. 1982). The other part was digested with MBN. After phenol/chloroform extraction and ethanol precipitation, the 2 nucleic acid preparations were separately ligated with the T4 ligase into the dephosphorylated Smal site of the pUC 18 vector. Competent Escherichia coli DH5- $\alpha$ cells were used for the transformation. The screening of the clones obtained was accomplished by alkaline lysis minipreps. The plasmids were analysed by agarose gel electrophoresis and those of interest were characterized with restriction enzymes.

Probe labelling. The Genius $I^{\mathrm{TM}}$ kit (Boehringer) was used according to the manufacturer's direction for labelling (incorporation of digoxigenin (DIG-11 dUTP) by the random primed labelling method), hybridization (10 ng of labelled DNA $\mathrm{ml}^{-1}$ of hybridization buffer) and detection (with anti-digoxigenin Fab antibody fragment labelled with alkaline phosphatase). Southern transfer (Maniatis et al. 1982) and dot-blot tech- niques (according to the method suggested in the application manual of the manufacturer) were performed on positively charged nylon membranes (Boehringer).

In situ hybridization. HPV-infected and uninfected Pemaeus chinensis, and other penaeid shrimp were fixed in Davidson's fixative according to the protocol described by Bell \& Lightner (1988). Sections, 4 to $5 \mu \mathrm{m}$ thick, were used for in situ hybridization using nonradioactive DIG-11 dUTP-labelled probes according to the technical manual from the manufacturer (Boehringer).

\section{RESULTS}

\section{Construction of genomic libraries}

Since it was unknown if the extracted DNA was single-stranded (ss) or double-stranded (ds), 2 strategies were used for the cloning: the first presumed the presence of a ssDNA-extracted genome (with the synthesis of a second strand using the Klenow polymerase), and the other presumed the existence of dsDNA (with the acquisition of a blunt-ended DNA using the $\mathrm{MBN}$ ). The transformation efficiency was very low for the 2 constructed libraries, with 600 and 800 clones (white colonies) isolated, respectively.

The screening was performed on about $50 \%$ of the 2 differently constructed libraries. Except for the plasmid from the clone OF44, all the other isolated plasmids had small insert sizes ranging from 100 to $200 \mathrm{bp}$. The OF44 clone was obtained from the first library (after repairing of the DNA with the Klenow enzyme), and it had an insert size of $2.3 \mathrm{kbp}$.

\section{Insert mapping}

The OF44 plasmid was digested with various restriction enzymes in order to construct a restriction enzyme map of its $2.3 \mathrm{kbp}$ insert. The following enzymes each had 1 site on the insert: Eco RI, Pst I, Xba I, Hinc II, Acc I, Sac I, Kpn I and Eco RV. The enzymes Bam HI, Hind III, Sal I and Bgl II did not possess any sites on the insert. The map of the insert is given in Fig. 1

\section{Probe preparation and specificity}

The OF 44 plasmid was digested by Acc I or by Sac I and after electrophoresis in low melting point agarose, the 2 restriction fragments obtained $(1.9$ and $2.0 \mathrm{kbp}$, respectively) were recovered using the agarase enzyme. They were labelled with DIG-11 dUTP and 


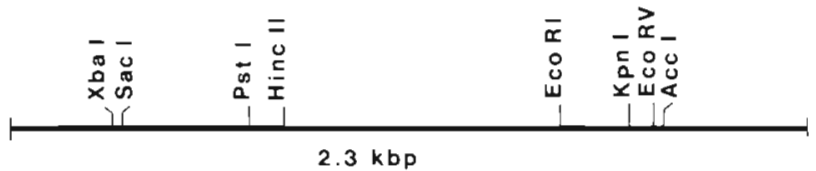

Fig. 1. Restriction map of the OF44 insert

the corresponding probes were named A-1.9 and S-2.0. The first specificity tests were done by dot-blots using log dilutions of HPV DNA, purified virions, and homogenized hepatopancreata of HPV-infected and healthy shrimp. The results, identical for A-1.9 and S-2.0, demonstrated a strong hybridization with the HPV-extracted DNA, the purified virus, and the homogenized infected tissues. However, a weak reaction, identical and independent of the dilutions used, was obtained with the healthy shrimp tissues and the higher dilutions of HPV-containing samples. Further tests demonstrated a weak cross-reaction of the probes with the dilution buffer (TE containing $50 \mu \mathrm{g} \mathrm{ml}^{-1}$ herring sperm DNA) from the Genius I ${ }^{\mathrm{TM}}$ Kit. Later dilutions were made in TE buffer or in TE buffer containing $50 \mu \mathrm{g} \mathrm{ml}^{-1}$ salmon sperm DNA and no more cross-reaction was noted. This modification of the dilution buffer confirmed the specificity of the probes against HPV (DNA, virus, infected shrimp) and the absence of hybridization with homogenized tissues from healthy shrimp.

Dilutions of phage Lambda DNA, pUC 18 plasmid, pBR 328 plasmid and DNA from IHHNV, another shrimp parvovirus (Lightner et al. 1983, Bonami et al. 1990, Lightner 1993, Mari et al. 1993), were also tested in dot-blot against the 2 probes. No reactions were obtained with the phage Lambda DNA and the IHHNV DNA. Weak reactions were noted with the pUC 18 and pBR 328 plasmids and these were interpreted as due to contamination by small fragments of the pUC 18 during the preparation of the inserts.

\section{HPV DNA study by Southern transfer}

The S-2.0 probe reacted with the total extracted HPV DNA, and was used to characterize this genomic DNA after agarose gel electrophoresis and Southern transfer. The probe reacted strongly with the band located at 4 to $4.3 \mathrm{kbp}$, which corresponds to ssDNA (Bonami et al. in press) and with the smear of degraded viral DNA (Fig. 2). Depending on the different DNA extractions, we have noted variations in these results, in particular the presence of more or less large smears containing bands looking like ladders. These results reflect the marked fragility of the extracted genomic $\mathrm{DNA}_{;}$on the other hand, without the use of the probes,
Fig. 2. Southern transfer of a $1 \%$ gel electrophoresis hybridized with the S-2.0 probe. Lane 1: DIG-labelled DNA molecular weight marker II; lanes 2 and 3 : 2 different preparations of HPVextracted DNA; the smear containing bands indicates the marked fragility of this DNA

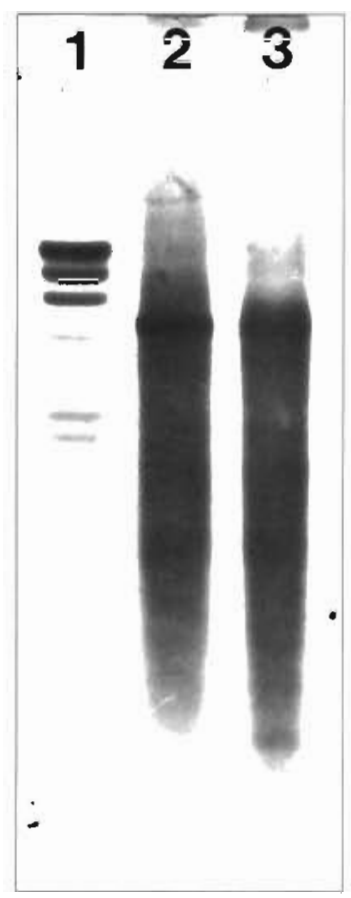

it was quite impossible to detect these degraded bands which indicate the fragility of the genome.

\section{In situ hybridization}

The S-2.0 probe was tested by in situ hybridization on paraffin-embedded sections of HPV-infected and healthy shrimp. No reaction was found in uninfected shrimp tissues. In HPV-infected shrimp sections, a strong positive hybridization was obtained in the hepatopancreatic cells (Figs. 3 to 5 ). This finding underlines the specificity of this probe against HPVinfected material. The hypertrophied nuclei of infected cells were strongly labelled and some cytoplasmic reaction was noted. In heavily infected hepatopancreata, a pronounced reaction was noted in the microvilli of the epithelial cells (Fig. 3). Basal to the microvilli in some cells were probe-positive vesicles (Fig. 4), which by their location and shape suggest that they could be pinocytotic in origin; therefore, HPV may infect cells by first attaching to the microvilli and then entering the cell by pinocytosis. Other cells, in apparently uninfected tubules, were also labelled at only the level of the microvilli, which we intrepret as due to the attachment of HPV released by necrotic cells elsewhere in the hepatopancreas. On the other hand, the nuclear 'inclusion body' (Lightner \& Redman 1985), a prominent feature in routine HPV histological diagnosis (Fig. 6), was found to be a little less reactive to the 


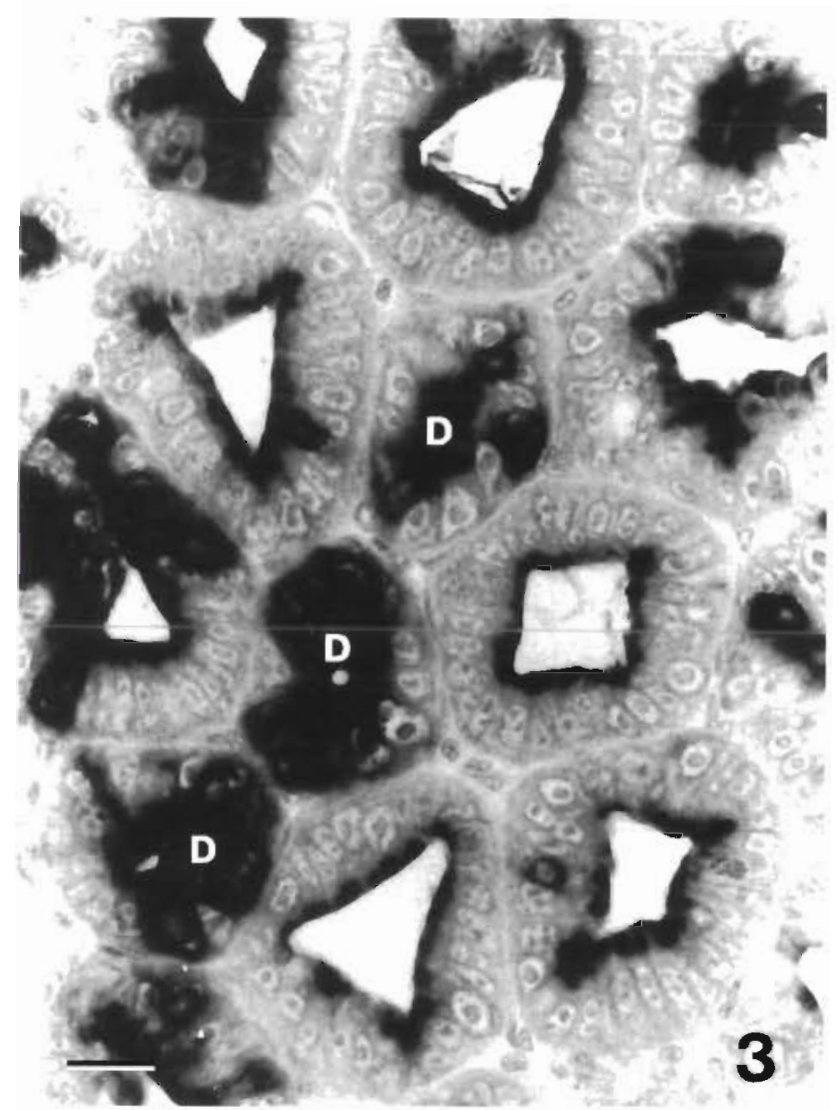

Fig. 3. In situ hybridization using the S-2.0 probe of an histological section of the hepatopancreas from a heavily HPVinfected juvenile Pendeus chinensis. Several HPV-positive foci involving epithelial cells display intense positive reactions for HPV with the probe. The lumens of several tubules are filled with HPV-positive cell debris (D). Probe hybridiza-

tion plus bismark brown counterstain. Scale bar $=20 \mu \mathrm{m}$

probe than were other probe-positive areas within the nucleus, but surrounding the inclusion body (Figs. 4 \& 5).

The only sectioned tissues that reacted with the S-2.0 HPV probe by in situ hybridization were the epithelial cells of the anterior midgut and hepatopancreas. These also were the only cells considered to be target tissues for the virus on the basis of routine histological examination (Lightner 1993).

In situ hybridization assays using the S-2.0 probe on shrimp sections infected with IHHNV were negative, underlining the strict specificity of the probe to HPV.

\section{DISCUSSION}

As postulated by Bonami et al. (in press), the extracted viral nucleic acid was a mixture of ss-and dsDNA. Therefore, our cloning strategy was designed

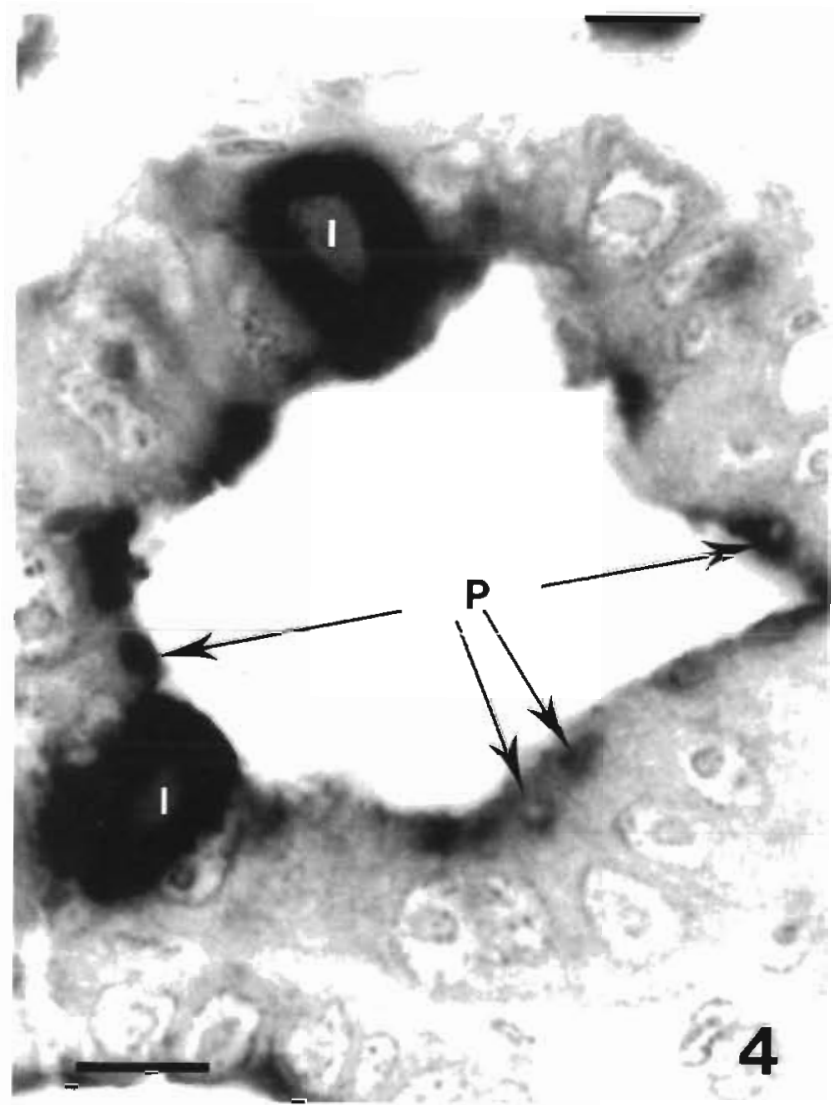

Fig. 4. A higher magnification view of a single hepatopancreatic tubule. Two cells with classic HPV intranuclear inclusion (I) bodies are well shown. Probe-positive areas on the surfaces of otherwise normal appearing epithelial cells bordering the lumen illustrate attachment of the virus to the surface of the microvilli and cellular uptake of the virus by pinocytoticlike $(\mathrm{P})$ vesicles. Probe hybridization plus bismark brown counterstain. Scale bar $=10 \mu \mathrm{m}$

based on these data, i.e. the acquisition of the dsDNA by $M B N$ digestion and, alternatively, the synthesis of a second strand of the viral ssDNA using the polymerase I, Klenow fragment. The clonings were only minimally successful in terms of number of clones obtained and the size of the insert. Only 1 clone was isolated, OF44, which carried a plasmid with a large insert size of $2.3 \mathrm{kbp}$. The restriction map of the OF44 insert showed no similarity when compared to the maps of 5 cloned DNA fragments of the IHHNV (Mari et al. 1993)

The 2 constructed probes tested (A-1.9 and S-2.0) demonstrate a high degree of specificity for HPV in infected tissue, without any cross-reactivity with healthy shrimp tissues. No hybridization was noted with extracted IHHNV DNA or with IHHNV-infected tissues in in situ hybridization. This result confirms the absence of homology between the 2 shrimp parvoviruses, HPV and IHHNV, as previously reported by 


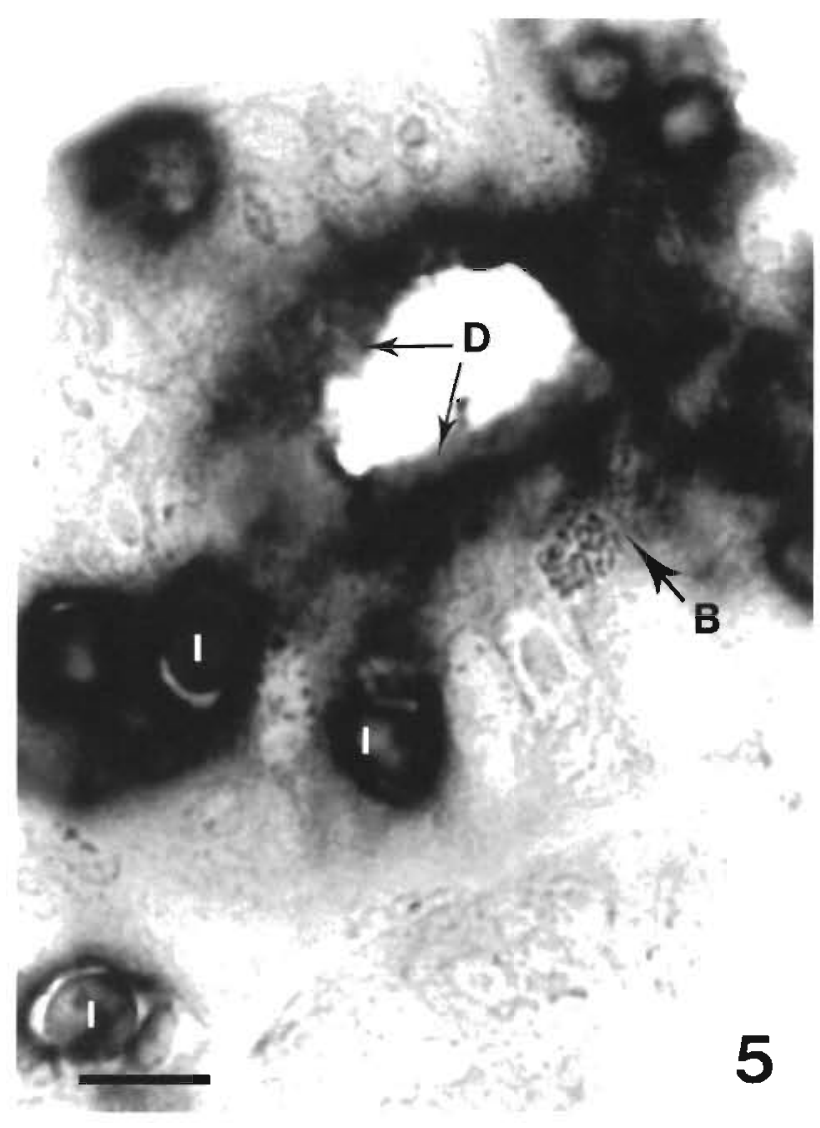

Fig. 5. Hepatopancreatic tubule which shows well some details of HPV infected cells. A few classic HPV intranuclear inclusion bodies (I), some with an artifactual halo, demonstrate a moderately dark reaction to the S-2.0 probe. Also present are intensely HPV-positive intranuclear areas surrounding the inclusion bodies and HPV-positive cell apices and cellular debris (D) within the tubule lumen. There is a microcolony of bacteria (B) in a cell adjacent to an intensely HPVpositive necrotic cell. Probe hybridization plus bismark brown counterstain. Scale bar $=10 \mu \mathrm{m}$

Mari et al. (1993) based on the absence of hybridization of a specific IHHNV probe (BS 4.5) against HPV DNA.

HPV-infected hypertrophied nuclei were strongly labelled by in situ hybridization. The luminal surface of hepatopancreatic epithelial cells were also labelled by the probe. Because cell surface labelling was most common in tubules with HPV-infected cells that displayed typical cytopathology and in heavily infected hepatopancreata, we interpreted the reaction of cells as indicative of the infection process. Hence, we interpreted the microvillar labelling of apparently healthy cells (without labelling reaction at the nucleic level) as the first step of infection, i.e. adsorption and uptake of viral material by the cell. The less intense labelling of the 'inclusion body' of the nucleus, as compared to the

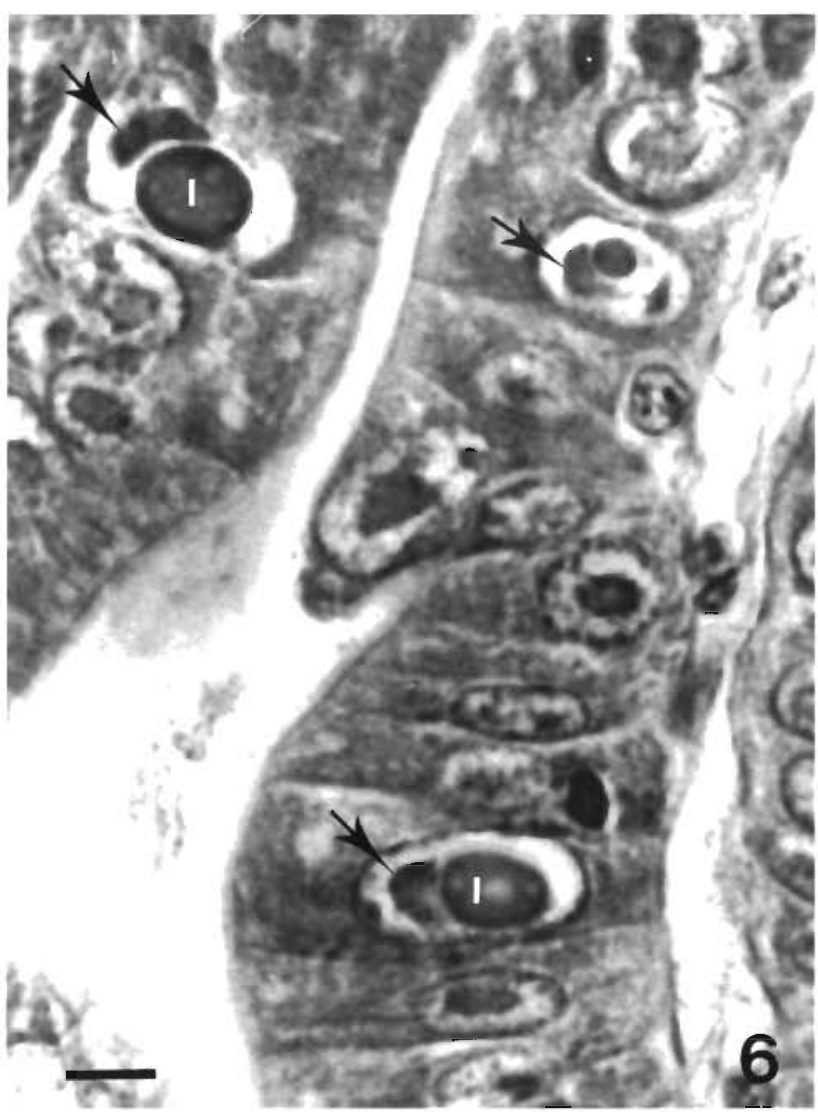

Fig. 6. Histological section of the hepatopancreas of an HPVinfected juvenile Penaeus chinensis. Prominent basophilic intranuclear inclusion bodies (1) diagnostic of $\mathrm{HPV}$ infection are shown in a number of epithelial cells. A prominent feature of HPV-infected nuclei in penaeid shrimp is the lateral displacement of the nucleolus (arrows) by the often haloed developing viral inclusion body. H\&E stain. Scale bar $=10 \mu \mathrm{m}$

rest of the nucleoplasm, could be explained by the hypothesis that this part of the virogenic area is more involved in protein synthesis than in viral nucleic acid synthesis.

These HPV probes constitute the second group of genomic probes constructed for the diagnosis of parvovirus diseases of marine prawns. They are in routine use at the University of Arizona Aquaculture Pathology Laboratory for the diagnosis of HPV in penaeid shrimp and they are particularly useful for the detection of low grade infections.

Acknowledgements. This work was funded by grants from the U.S. Department of Agriculture, Marine Shrimp Farming Consortium grant no. 88-38808-3320, U.S. Department of Commerce, N.O.A.A., Asian Interchange Program administered by the Oceanic Institute in Hawaii, by the National Sea Grant Program, N.O.A.A., U.S.D.C., and by the French Centre National de la Recherche Scientifique. 


\section{LITERATURE CITED}

Bell TA, Lightner DV (1988) A handbook of normal Penaeid shrimp histology. World Aquaculture Society, Baton Rouge

Bonami JR, Bruce LD, Poulos BT, Mari J, Lightner DV (1995) Partial characterization and cloning of the genome of PvSNPV (= BP-type virus) pathogenic for Penaeus vannamei. Dis aquat $O r g$ (in press)

Bonami JR, Lightner DV (1991) Unclassified viruses of Crustacea. In: Adams JR, Bonami J-R (eds) Atlas of invertebrate viruses. CRC Press, Boca Raton, p 597-622

Bonami JR, Mari J, Poulos BT, Lightner DV (in press) Characterization of the HPV, a second unusual parvovirus pathogenic for penaeid shrimp. J gen Virol

Bonami JR, Trumper B, Mari J, Brehelin M, Lightner DV (1990) Purification and characterization of the infectious hypodermal and haematopoietic necrosis virus of penaeid shrimps. J gen Virol 71.2657-2664

Bruce L, Redman RM, Lightner DV, Bonami JR (1993) Application of gene probes to detect a penaeid shrimp baculovirus in fixed tissue using in situ hybridization. Dis aquat Org 17:215-221

Lightner DV (1993) Diseases of penaeid shrimp. In: McVey JP (ed) CRC handbook of mariculture, 2nd edn, Vol 1. Crustacean aquaculture. CRC Press, Boca Raton, p 393-486

Lightner DV, Redman RM (1985) A parvo-like virus disease of Penaeid shrimp. J Invertebr Pathol 45:47-53

Responsible Subject Editor: J. E. Stewart, Dartmouth, Nova Scotia, Canada
Lightner DV, Redman RM (1992) Penaeid virus diseases of the shrimp culture industry of the Americas. In: Fast AW, Lester LJ (eds) Marine shrimp culture: principles and practices. Elsevier Science Publishers BV, Amsterdam, p 569-588

Lightner DV, Redman RM, Bell TA (1983) Infectious hypodermal and hematopoietic necrosis, a newly recognized virus disease of penaeid shrimp. J Invertebr Pathol 42:62-70

Maniatis T, Fritsch EF, Sambrook J (1982) Molecular cloning. A laboratory manual. Cold Spring Harbor Laboratory, Cold Spring Harbor, NY

Mari J, Bonami JR, Lightner DV (1993) Partial cloning of the genome of infectious hypodermal and haematopoietic necrosis virus, an unusual parvovirus pathogenic for penaeid shrimps; diagnosis of the disease using a specific probe. J gen Virol 74:2637-2643

Poulos BT, Lightner DV, Trumper B (1994a) Monoclonal antibodies to a penaeid shrimp parvovirus, infectious hypodermal and hematonoletic necrosis virus (IHHNV). J Aquat Anim Health 6:149-154

Poulos, BT, Mari J, Bonami JR, Redman R, Lightner DV (1994b) Use of non-radioactively labeled DNA probes for the detection of a baculovirus from Penaeus monodon ( $\mathrm{PmSNPV}=\mathrm{MBV}$ ) by in situ hybridization on fixed tissue $J$ virol Meth 49:187-194

Sambrook J, Fritsch EF, Maniatis T (1989) Molecular cloning A laboratory manual, 2nd edn, Vols $1-3$. Cold Spring Harbor Laboratory, Cold Spring Harbor, NY

Manuscript first received: August 3, 1994

Revised version accepted: October 31, 1994 